
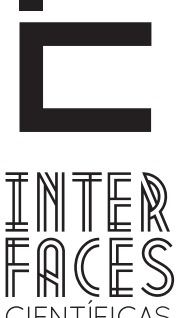

CIENTÍFICAS

HUMANASE SOCIAIS

\title{
MAPAS CONCEITUAIS NA PESQUISA DO DIREITO AMBIENTAL E NA FORMAÇ̃̃O DE PROFESSORES
}

Giselle Marie Krepsky ${ }^{1}$

Willian J. Goetten ${ }^{3}$
Eliana Pacheco Morastoni ${ }^{2}$

\section{RESUMO}

Este artigo aborda o uso de Mapas Conceituais com softwares específicos no desenvolvimento de pesquisa científica na área de Direito Ambiental bem como na formação de professores. A experiência é realizada por meio dos Seminários do Projeto Rede Guarani/Serra Geral que possibilitaram o estudo da proteção jurídica das águas na legislação constitucional do Brasil. 0 referencial teórico da proposta é baseado na aprendizagem por conceitos. A pesquisa concluiu que os mapas conceituais podem ser utilizados como recurso metodológico para a apropriação de conceitos, para a produção e a organização de dados, para a produção do conhecimento científico de pesquisa em desenvolvimento bem como para o aprimoramento didático dos docentes.

\section{PALAVRAS-CHAVE}

Mapas Conceituais. Pesquisa Jurídica. Formação de Professores. Projeto Rede Guarani/Serra Geral. Produção do Conhecimento. 


\section{ABSTRACT}

This article discusses the use of conceptual maps with specific software on the development of scientific research in the area of environmental law as well as in teacher training. The experiment is performed through Seminars of the Guarani Network Project - Serra Geral that made possible the study of the legal protection of waters in Constitution legislation of Brazil. The theoretical referential of the proposal is based on learning through concepts. The completed survey concluded that conceptual maps can be used as a methodological resource for the appropriation of concepts, for the production and data organization for the production of scientific knowledge in research and development as well as for the improvement of the teaching faculty.

\section{KEYWORDS}

ConceptualMaps. Legal Research. Teacher Learning. Guarani Network Project - Serra Geral. Knowledge Production.

\section{RESUMEN}

Este artículo aborda el uso de mapas conceptuales con software específico en el desarrollo de la investigación científica en el área de Derecho Ambiental y en la formación de profesores. El experimento se realizó a través de lo Proyecto Red Guaraní/ Serra Geral, que hizo posible el estudio de la protección jurídica de las aguas en el derecho constitucional del Brasil. El marco teórico de la propuesta se basa en la aprendizaje a través de conceptos. La investigación concluyó que los mapas conceptuales pueden ser utilizados como un recurso metodológico para la apropiación de conceptos para la producción y organización de datos, para la producción de conocimiento científico en la investigación en desarrollo, así como para la mejora de la didáctica del profesorado.

\section{PALABRAS-CLAVE}

Mapas conceptuales. Investigación jurídica. Formación de profesores. Producción de conocimiento. 


\section{INTRODUÇ̃̃O}

Este artigo aborda resultados do projeto de extensão do Grupo de Pesquisa em Direitos Fundamentais, Cidadania e Novos Direitos da Fundação Universidade Regional de Blumenau (FURB) e apresenta a metodologia dos Mapas Conceituais (MC) com a utilização de ferramentas específicas utilizada para o desenvolvimento dos "Seminários do Projeto Rede Aquífero Guarani/Serra Geral 2012". O projeto de extensão dos Seminários faz parte do Projeto Rede Guarani/Serra Geral (RGSG) 4 que tem a participação de outras sete ${ }^{5}$ instituições de Santa Catarina com financiamento da Fundação de Amparo a Pesquisa e Inovação do Estado de Santa Catarina (FAPESC).

Elaborar propostas que atendam a uma nova abordagem de gestão integrada e participativa, utilizando para esse fim ferramentas pedagógicas e didáticas, é meta elementar do Projeto RGSG. Cabe ressaltar que, de acordo com Wolkmer, Scheibe e Henning (2011), a concepção geral do projeto visa proporcionar: infraestrutura, capacitação e intervenção. Dessa forma a comunidade acadêmico-científica comprometeu-se em buscar soluções a fim de desenvolver uma concepção sustentável do uso da água, em que os agentes envolvidos passam a compreender a água a partir do conhecimento pré-estabelecido sobre o assunto. Tal concepção deve estar embasada em diálogos interdisciplinares, na inovação tecnológica, assim como na sabedoria local que ensina maneiras práticas de se conduzir a gestão. Intensificar o intercâmbio de experiências exitosas e divulgar suas práticas faz parte de um processo que busca desenvolver um modelo de governança ideal.

Neste projeto, coube ao Grupo de pesquisa em Direitos Fundamentais, Cidadania e Novos Direitos do Curso de Direito da FURB analisar os aspectos jurídicos relativos à gestão das águas subterrâneas

4. A área de abrangência do Aquífero Guarani/ Serra Geral é de aproximadamente de $1.195 .000 \mathrm{~km}^{2}$, sendo que, no Brasil, estão localizados $71 \% \mathrm{da}$ área total do aquífero, o que representa 9,9\% do território nacional (ARAÚJO; FRANÇA; POTTER, 1995).

5. UFSC, Epagri, UNOESC, Uniplac, UDESC, UNOCHAPECÓ, UnC. do Sistema Aquífero Integrado Guarani/Serra Geral (SAIG/SG). No projeto, a água é assumida como um direito humano fundamental que deve atender a necessidades básicas de sobrevivência. Nesse contexto, Pompeu (2011) assevera que a perspectiva adotada na pesquisa jurídica não é de mera institucionalização de direitos, posto que a construção de direitos é um processo participativo de saberes.

Diante disto, o objetivo geral dos Seminários foi promover uma reflexão sobre os aspectos jurídicos que envolvem a gestão do SAIG/SG articulada com uma visão interdisciplinar por meio da metodologia dos Mapas Conceituais. No que se refere aos objetivos específicos, ressaltam-se: a) oportunizar um espaço de discussão sobre a pesquisa que vem sendo desenvolvida no âmbito do Projeto RGSG com a comunidade acadêmica; b) propiciar ao corpo docente e discente do curso de Direito uma vivência direta com a pesquisa científica a partir de uma visão interdisciplinar; c) estimular a produção coletiva de artigo científico relacionado à Meta $4 \mathrm{Com}$ ponente $2^{6}$ do Projeto RGSG como produto final dos seminários de pesquisa; d) Capacitar os docentes participantes para o uso da metodologia de Mapas Conceituais em suas disciplinas.

Foram utilizadas as propostas de Moreira e Masini (2002) Moreira e Buchweitz (1987) e Novak e Gowin (1984) que têm como base teórica a ideia da aprendizagem significativa de David P. Ausubel. Para Ausubel (apud MOREIRA; BUCHWEITZ, 1987, p. 16) quando:

[...] novas informações adquirem significado para o indivíduo através da interação com conceitos existentes, sendo por esses (sic) assimiladas e contribuindo para sua diferenciação, elaboração e estabilidade, a aprendizagem é dita significativa.

6. Análise da natureza jurídica da água e suas implicações com questões de outorga e competência legislativa no Brasil. 
Os mapas conceituais são "diagramas hierárquicos indicando os conceitos e as relações entre esses conceitos. [...] sua existência é derivada da estrutura conceitual de uma fonte de conhecimentos" (MOREIRA; BUCHWEITZ, 1987, p. 9). 0 projeto foi desenvolvido com base nos conceitos que exigiam aprimoramento teórico para o alcance das metas do Grupo de Pesquisa e abrangeram o aprofundamento horizontal e vertical a partir da inter-relação com outros conceitos ou subconceitos da mesma área ou correlatas, porém necessários à compreensão daqueles, posto que é de caráter interdisciplinar. Os conceitos eleitos foram: Recursos Hídricos e Águas.

\section{BASE TEÓRICA E PROPOSTA}

De acordo Novak e Gowin (1984, p. 31) a utilização dos MC serve para clarificar as principais ideias chave a fim de privilegiar uma aprendizagem específica. Além disso, o MC pode sinalizar caminhos cognitivos desse processo para os quais se deve seguir, bem como estabelecer ligações entre essas ideias ou conceitos e que acabam de forma esquemática representando o que se aprendeu.

Para Moreira e Buchweitz (1987, p. 11) esses diagramas ou representações esquemáticas acabam por refletir a organização conceitual de uma disciplina ou parte dela, de um livro, artigo ou até mesmo de um experimento laboratorial, da estrutura cognitiva de um indivíduo [ou grupo de pesquisadores/alunos como na presente proposta] sobre um dado assunto. Assim, o MC utilizado como parâmetro de organização dos seminários foi construído previamente pelos membros do grupo, por levar em consideração os conhecimentos prévios existentes bem como as necessidades conceituais dos participantes. Portanto, o MC originariamente construído pôde ser alterado e complexificado na medida em que os estudos individuais ou coletivos avançaram e que novos conceitos surgiram como elos necessários.
Em se tratando da aprendizagem de adultos, de maneira bastante rudimentar, explica-se como esse processo ocorre, tomando como ponto de partida quando um novo fato, informação (esquema mental) é apresentada. 0 conhecimento prévio é organizado mentalmente por meio de vários esquemas e subesquemas de conhecimentos, conceitos, aprendizagens, aos quais o novo deverá se integrar.

Para Krepsky (2006) quando surge um novo fato, informação ou conhecimento (esquema) a ser adquirido, ocorre um desequilíbrio no sistema mental, que se manifesta por meio da necessidade de reequilibrá-lo. Esse novo esquema pode se integrar ao sistema total anterior quando os elementos exteriores se incorporam aos internos ou quando se complementam reciprocamente, ocasionando assim a assimilação do novo. Quando o sistema cognitivo total estiver adaptado como o novo exterior, ocorre uma acomodação e pode-se dizer que se encontra novamente equilibrado. Esta passagem assimilação - acomodação é contínua e essencial para a manutenção do equilíbrio das estruturas cognitivas. Estas passagens são progressivas e nunca atingem um estágio final de equilíbrio, por ser infinita a construção de novas estruturas mentais.

Logo, conforme precisou Piaget (1969) toda necessidade ocasionada por um desequilíbrio tende a fazer com que o mundo exterior se incorpore ao interior do sujeito, somando-se às estruturas já construídas, ou fazendo-se um reajustamento destas em relação àquelas. Então, conforme destaca Krepsky (2006) para o sujeito assimilar esse novo conhecimento, ele terá que incorporá-lo aos seus esquemas anteriores sem perdê-los, mas reestruturando-os. As incorporações de novos esquemas mentais ligando-se aos anteriores podem ser equiparadas, de forma análoga, a uma teia de conhecimentos que dá aos elementos do mundo exterior paulatinas significações. Por isso, a utilização dos mapas conceituais também se torna ferramenta apropriada sob o ponto de vista metodológico. 
No que se refere à capacitação docente, não se pode esperar que um mero treinamento de professores em curto prazo possa trazer resultados para todo um curso e muito menos para toda uma transformação no ensino jurídico a ponto de refletir transformações no próprio aparato jurídico. Em primeiro lugar, porque nem sempre a proposta inovadora é facilmente aceita, especialmente quando se trata de um terceiro que a oferta, porque para isso é preciso que o professor se coloque diante de uma necessidade particular, pessoal ou até mesmo que se exponha como um docente que possui dificuldades profissionais e pedagógicas. Em segundo lugar, porque ofertar apenas treinamentos, cursos ou trabalho de apoio pedagógico que não estejam plenamente inseridos no contexto e sejam dotados de uma compreensão do cotidiano e das especificidades dele, podem ser consideradas instruções vazias de significado e aplicação. Em terceiro lugar, porque generalizar o processo de formação em tempo, local e espaço, é ir de encontro à própria essência do processo de apropriação dos conceitos, que inicialmente exigirá um problema a ser resolvido e culminará no processo de reelaboração conceitual que é idiossincrático (KREPSKY, 2006).

Eis aí uma grande contribuição da pesquisa no plano da aprendizagem, posto que possibilita a reconstrução e o aprimoramento conceitual de qualquer aprendente. Para Demo (2000, p. 28-29) esse conhecimento reconstrutivo se inicia exatamente com o saber efetuar uma busca e a partir disto questionar (pesquisa). Após a iniciativa de buscar fontes, manejar dados e conhecimento disponível exercerá um questionamento sistemático sobre o material disponível, que, por sua vez, fomentará o espírito crítico. E deixa-se para trás a condição de objeto. É neste sentido que a organização de mapas conceituais, se mostra contributiva, na medida em que auxilia esta sistematização. Assim, Morin (2008, p. 18) resume a atividade do conhecimento em três esferas necessárias:

a) uma competência (aptidão para produzir conhecimentos); b) uma atividade cognitiva (cognição), realizando-se em função da competência; c) um saber (resultante dessas atividades). [...] É nesse quadro que o espírito humano elabora e organiza o seu conhecimento utilizando os meios culturais disponíveis.
Assim sendo, destaca-se que três elementos são essenciais para o desenvolvimento desta proposta metodológica: a) o público e seu conhecimento prévio; b) os conceitos de interesse e os que se tornarão os geradores; c) a estratégia metodológica para complementação e preenchimento dos mapas.

De acordo com Moreira e Buchweitz (1987, p. 29-30) são utilizados os seguintes passos na elaboração de um mapa conceitual: 1- localizam-se os conceitos; 2- listam-se os conceitos em uma ordem hierárquica; 3 - distribuem-se os conceitos em duas dimensões; 4-traçam-se as linhas que indicam as relações entre os conceitos; 5- escreve-se a natureza da relação; 6 - revisa-se e refaz-se o mapa; 7prepara-se o mapa final.

Considerando-se que boa parte dos mapas conceituais inicia-se por conectores que representam perguntas, sugeriu-se que o MC que serve de referência para a realização dos seminários, também, fosse iniciado por questões-problemas que dizem respeito aos conceitos geradores eleitos ou até mesmo aos objetivos do grupo com relação à pesquisa. Igualmente, as palavras-chave podem constituir-se de categorias expressas por conceitos operacionais específicos.

Logo, considerando-se as temáticas iniciais ou categorias: Recursos hídricos e Águas, muitos mapas conceituais iniciais podem ser elaborados. E essa multiplicidade ou complexidade dos mapas pode variar de acordo com o conhecimento prévio médio do grupo. É claro que, alguns membros podem não possuir conhecimentos prévios básicos, levando-se em consideração as áreas de origem, trabalho, experiência e nível de especialização. Este eventual impasse deve ser resolvido pela simplificação do mapa inicial e com a reelaboração posterior ou com a exigência de apropriação individual e "mecânica" destes conhecimentos até que se tornem significativos. 0 que não se recomenda é que os membros do grupo participem de muitas sessões plenárias sem que se efetive a apropriação conceitual. 
Ainda no que tange à elaboração do MC inicial, sugere-se que a primeira pergunta genérica que deve ser feita é: o que é que se considera importante conhecer e aprofundar diante da temática (conceitos) proposta? Daí podem surgir imediatamente os primeiros subconceitos. Uma vez eleitos os primeiros subconceitos escreve-se a natureza da relação com os conceitos geradores ou iniciais, por ora denominada simplesmente de conectores e que podem também ser as situações-problema inerentes a estes conceitos. Interessante frisar que o MC inicial deve ser levado para as sessões plenárias, e se possível ser elaborado com cartões móveis, pois, na medida em que as discussões avançam, podem ser agregadas outras relações necessárias e dantes não imaginadas e que, porventura, fomentarão novos seminários.

Além do instrumento principal que são os textos específicos por conceito e subconceitos, considera-se interessante e até mesmo necessário o convite de profissionais (da academia ou não) para trabalhar conceitos de áreas das quais os membros do grupo não possuem conhecimento prévio necessário até mesmo para escolher bons textos, ou porque a inclusão de outros profissionais seja mais profícua na elucidação do MC original. Ademais, Novak e Gowin (1984, 69-70) recomendam que para o fechamento do estudo por mapas conceituais, deve-se obrigatoriamente contemplar a elaboração de mensagens [produções] escritas ou orais e que devem ser sequências lineares de conceitos ou proposições, muito embora o conhecimento se armazene em estruturas não lineares. Portando, as sequências hierárquicas elaboradas para assimilação podem e até devem ser transformadas em estruturas lineares na escrita. Nesse tocante, o uso de mapas conceituais está diretamente imbricado com a produção e divulgação de conhecimento no contexto universitário.

Sinteticamente, sugere-se que sejam seguidos os seguintes passos metodológicos: a) definição dos objetivos de conhecimento do grupo e elaboração do $M C$ prévio na primeira sessão; b) escolha dos conceitos/subconceitos e textos a serem apresentados pelos membros do grupo no
$1^{0}$ Seminário; c) elaboração de produção textual (resumo) dos textos selecionados seguindo roteiro específico ${ }^{7}$; d) disponibilização da produção textual com antecedência; e) realização do Seminário para a apresentação e discussão dos textos com a alteração ou não do $\mathrm{MC}$ inicial que deve ser disponibilizado no encontro por meio de cartões móveis. Nesta mesma sessão devem ser definidos os novos conceitos/subconceitos a serem trabalhados por outro subgrupo em nova sessão ${ }^{8}$.

\section{APLICAÇ̃̃O DA PROPOSTA: AMPLIANDO 0 CONHECIMENTO CIENTÍFICO SOBRE AS ÁGUAS E AS COMPETÊNCIAS LEGISLATIVAS PARA SUA GESTÃO NO BRASIL}

Para efetivação da proposta foram realizados 7 (sete) seminários, sendo 6 (seis) semipresenciais e 1 (um) virtual. Totalizando ao final 63 (sessenta e três) horas de atividades. Neste encontro, havia 15 (quinze) participantes dentre eles: 7 (sete) professores do Curso de Direito, 1 (uma) mestranda do Programa de Mestrado em Desenvolvimento Regional da FURB e 7 (sete) acadêmicos do Curso de Direito da FURB, destes, 5 (cinco) bolsistas do Grupo de Pesquisa. Desta equipe, apenas uma professora já possuía contato com a metodologia de ensino por mapas conceituais, mas não utilizava ferramentas específicas.

Os participantes tiveram acesso ao material antecipadamente de forma virtual, sendo que, nesse primeiro seminário houve a definição do primeiro mapa conceitual sobre as principais categorias que deveriam ser estudadas para o terceiro seminário. De acordo com a proposta teórica, realizou-

7. Para a apresentação de resumos é disponibilizado um roteiro padrão de apresentação e análise textual a fim de que se possa compilar toda a produção ao final dos encontros para a elaboração de um artigo científico do grupo.

8. Em uma mesma sessão podem ser trabalhados mais de um conceito ou subconceito com subgrupos diferentes dependendo da dinâmica de apropriação dos membros do grupo. 
-se o nivelamento de conhecimentos do grupo participante e a definição dos conceitos básicos a partir dos quais os estudos deveriam se pautar. Importante destacar que, o ato do grupo discutir quais conceitos deveriam ser eleitos para o mapa inicial, já possibilitou a troca de conhecimento sobre a temática, posto que a todo momento houve argumentação sobre as categorias que envolviam a concretização da Meta 4, Componente 2 do Projeto RGSG. Assim, o Mapa Inicial foi composto das seguintes categorias:

Fiqura - 4 Mapa Inicial

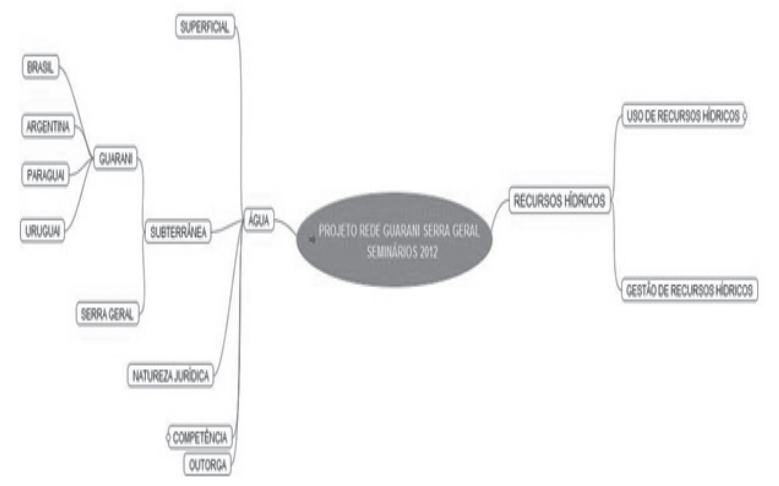

Fonte: Elaborado pelos participantes dos Seminários

O segundo seminário presencial contou com a capacitação prévia para o uso dos softwares para elaboração de mapas conceituais, organização e compartilhamento de documentos como: freemind, dropbox e pearltrees. O freemind é um programa de software livre que serve para a elaboração de mapas mentais/conceituais, cujo donwnload pode ser feito facilmente e se adapta a diversos sistemas operacionais. O dropbox é uma ferramenta que serve para armazenar e compartilhar arquivos a partir de várias fontes: desktops, tablets, smartphones, etc., é do tipo cloud computing, ou seja, de armazenamento no conceito "nuvem". Esta ferramenta possibilita o usuário a acessar seus arquivos de qualquer máquina que tenha o software ou aplicativo instalado e também possibilita o acesso pela internet. Com o mesmo intuito, mas com plataforma diferente, o pearltrees serve para partilhar, armazenar e organizar conteúdos de internet a partir do perfil do usuário. A capacitação para o uso dessas ferramentas foi realizada com êxito. No entanto, ressalta-se que alguns professores ofereceram resistência ao uso das tecnologias num primeiro momento, precisando de mais tempo para se adaptar.

Esse seminário foi ministrado pelo professor Luiz Henrique Silva do Centro de Ciências Sociais Aplicadas da FURB que é especialista no uso de mapas mentais no ensino de Línguas e Administração. Dessa forma, a participação de um membro externo ao grupo dos Seminários se mostrou relevante, na medida em que as ferramentas apresentadas foram utilizadas pelos participantes até o final de todos os encontros, e, foram exatamente elas que se tornaram extremamente úteis para o trabalho em equipe, compartilhado de modo virtual com todos os membros.

O terceiro seminário contou com estudo e produção textual prévia dos participantes, bem como elaboração de mapas conceituais já com a utilização das ferramentas citadas acima. Foi criado um diretório específico para os Seminários do Aquífero no dropbox, e, a partir de então, todos podiam acessar os trabalhos, mapas e seleção de textos de todos os integrantes, possibilitando um trabalho em rede. Salienta-se que o sistema permite que qualquer um que esteja adicionado ao grupo no dropbox acesse e modifique qualquer arquivo salvo no diretório virtual simultaneamente.

Para o aprofundamento dos conceitos eleitos para cada seminário foram escolhidos sempre dois textos para cada categoria: um clássico da literatura jurídica e outro com avaliação A ou B da QUALIS - CAPES. Com o recebimento prévio dos textos, os integrantes se distribuíram em grupos para a elaboração do mapa conceitual pertinente. 
No quarto seminário, houve troca de participantes, haja vista que alguns professores se afastaram da Universidade e que alguns acadêmicos bolsistas de pesquisa foram substituídos no Grupo de Pesquisa. Nesse momento, também ingressou na equipe, uma acadêmica do curso de Direito que estava elaborando seu Trabalho de Conclusão de Curso sobre a temática.

No que se refere à apropriação de conceitos, a partir do Mapa Inicial (Figura 1), todos os conceitos foram sendo relacionados e, na medida em que o aprofundamento dos conceitos vertical ocorria, outras categorias ou conceitos fundamentais para a compreensão deles surgiam. No entanto, foi no estudo do conceito competência que os integrantes perceberam muitas divergências no posicionamento da doutrina mais usual em Direito Ambiental e em Direito Constitucional. Assim, deliberou-se que seria aprofundado o estudo específico sobre as competências constitucionais gerais e ambientais, a fim de nortear um parâmetro para a gestão da água. Para este encontro, todos os participantes se encarregaram de elaborar mapas conceituais de acordo com uma lista prévia de obras e autores disponibilizados previamente (etapa à distância).

O quinto seminário contou com a discussão dos mapas conceituais produzidos pelos participantes bem como foram selecionados os destaques textuais mais importantes, realizando-se uma produção conjunta para posterior análise comparativa das semelhanças e contradições apontadas na literatura. Assim, cada integrante ou grupo de integrantes ficou responsável por elaborar o mapa conceitual das competências constitucionais para cada autor de forma livre, possibilitando assim a criatividade de cada um.

Após a discussão dos destaques textuais feitos com base nos mapas conceituais, foram elaboradas tabelas que evidenciavam a classificação das competências constitucionais feitas por cada autor. A análise comparativa dos doutrinadores possibilitou o esclarecimento dos pontos conflitantes com intuito de estabelecer para o Grupo de
Pesquisa a aplicação mais adequada das competências constitucionais das águas e eventuais conflitos, identificando, assim, possíveis implicações jurídicas sobre a gestão e proteção das águas.

O sexto seminário foi totalmente virtual e voltado para a conclusão dos mapas. O sétimo e último seminário realizou-se de forma presencial. Nele foi apresentado o balancete de toda a produção realizada nos demais seminários bem como o mapa mental do projeto para consubstanciar os objetivos e resultados, além de serem coletadas informações acerca da experiência dos participantes.

\section{AVALIACÃO DA PROPOSTA}

A análise e a avaliação da proposta foram feitas com base nos objetivos específicos do projeto bem como em outras categorias de análise a serem descritas, à luz do referencial teórico eleito. Quanto ao objetivo geral do Projeto pode-se afirmar que foi alcançado, muito embora a proposta inicial fosse adaptada. Isso porque, o tipo de produção textual e a metodologia por meio de mapas conceituais pensada originariamente foram adequados ao nível dos participantes e das possibilidades estruturais e temporais. O que vale ressaltar, é que um dos objetivos principais que era realizar uma reflexão sobre os aspectos jurídicos que envolviam o Projeto RGSG por meio de mapas conceituais, ocorreu.

Quanto aos objetivos específicos, considera-se de suma importância a oportunidade de criar um momento e espaço de discussão sobre a pesquisa que vem sendo desenvolvida no âmbito do Projeto RGSG com a comunidade acadêmica. Da mesma forma, esta proposta possibilitou ao corpo docente e discente do curso de Direito uma vivência direta com a pesquisa científica a partir de uma visão interdisciplinar, posto que foram trabalhados conteúdos de Direito Ambiental e de Direito Constitucional, além de contar com a colaboração de docente especialista na utilização de mapas conceituais no ensino. 
Ademais, a possibilidade de aumentar a discussão com a comunidade acadêmica, ainda que pequena, a respeito dos aspectos jurídicos da áqua no Brasil, também foi bem sucedida e, neste mesmo sentido, os trabalhos do Grupo de Pesquisa em Direitos Fundamentais, Cidadania e Novos Direitos da FURB também tiveram uma maior divulgação. Por consequência o objetivo de obter um grupo de pesquisadores (professores e alunos) mais coeso e comprometido com a produção científica também pôde ser verificado, paulatinamente.

0 estímulo à produção de artigo científico relacionado à Meta 4 Componente 2 do Projeto RGSG como produto final dos Seminários de pesquisa, também, se concretizou, posto que a participação e colaboração da acadêmica Monara Besen do Curso de Direito da FURB levou à aprovação de seu Trabalho de Conclusão de Curso orientado pela professora Coordenadora dos Seminários cujo título é: "Competência Constitucional sobre as águas: uma análise comparativa doutrinária" e que também foi publicado em artigo de divulgação científica.

Outro ponto importante a ser destacado foi a formação docente para o uso de novas ferramentas para a pesquisa e para o ensino. Para tanto, foram tomados como parâmetros de verificação dos níveis desta formação docente, os seguintes itens: a) Formação docente com desenvolvimento conceitual completo: para o caso de ser constatada a transferência autônoma dos conhecimentos sobre mapas conceituais e as ferramentas utilizadas para situações diversas (Ex.: outras situações de ensino-aprendizagem, vida profissional, vida pessoal, etc.); b) Formação docente para capacitação técnica: para o caso de ser constatada uma incorporação parcial dos conhecimentos sobre mapas conceituais de modo que não se tenha percebido uma transferência autônoma, ou não se tenha percebido qualquer transferência para outras situações diversas do uso da metodologia e ferramentas além dos Seminários; c) Não houve formação docente: para o caso de não ter ocorrido a apropriação da metodologia por mapas conceituais nem mesmo para a participação dos Seminários.
Ressalta-se que a formação de professores nos Seminários ocorreu de forma satisfatória, ou seja, com desenvolvimento conceitual completo. Isto porque muitos dos que participaram, relataram a utilização das ferramentas em outras atividades que exercem. Destaca-se a utilização de mapas e das ferramentas em disciplinas teóricas do Curso de Direito, bem como práticas no Estágio Curricular Obrigatório. Uma professora relatou ter usado até mesmo para organizar a vida profissional/pessoal.

Assim, resumidamente, os principais resultados positivos alcançados com o Projeto dos Seminários do Aquífero foram: avanço conceitual no que se refere às competências sobre as águas, com elucidação teórica a respeito da gestão das águas subterrâneas no Brasil; maior organização e compilação de dados das pesquisas envolvidas com o projeto; possibilidade de trabalho em rede entre os pesquisadores; facilidade de trabalho colaborativo e em equipe; fortalecimento do Grupo de Pesquisa; possibilidade de vivência da pesquisa para não pesquisadores; utilização dos dados produzidos durante os Seminários em publicações científicas e de relatório parcial do Projeto RGSG; capacitação técnica e apropriação do uso para o ensino e para a aprendizagem dos mapas conceituais; estímulo e fortalecimento da produção do conhecimento científico produzido no âmbito da Universidade.

Dentre as limitações ocorridas verificou-se: alteração do corpo discente e docente durante a execução da proposta, causando uma breve descontinuidade nas pesquisas e desenvoltura no uso das ferramentas; dificuldade inicial na elaboração dos mapas, considerando os diferentes estágios de conhecimento a respeito do objeto da pesquisa; impossibilidade de usar os conectores de conceitos por meio da ferramenta freemind ${ }^{9}$, tal qual sugerido na proposta; necessidade de notebooks com potência razoável para todos os integrantes para a realização das reuniões presenciais.

\footnotetext{
9. Para o uso livre de conectores sugere-se o uso da ferramenta Cmap Tools, para esta proposta o uso do freemind deu-se por sua maior facilidade de uso e carregamento nas máquinas
} 


\section{CONSIDERAÇÕES FINAIS}

Com o estudo evidencia-se que o modelo teórico apresentado pelos autores eleitos é amplamente difundido no meio acadêmico e pode ser adaptado para a aprendizagem de conceitos científicos inerentes a pesquisas em andamento de um determinado Grupo de pesquisadores.

Da mesma forma, a transposição prática da aprendizagem significativa por conceitos pode ser feita para a formação de professores com o intuito de aprimorarem sua didática. Nesse viés, o uso de ferramentas específicas para a criação de mapas conceituais serve de estímulo tanto para acadêmicos quanto para professores de graduação em Direito. Assim, se de um lado obteve-se o avanço nas pesquisas sobre a gestão das águas no Brasil, por outro, o Curso de Direito ganhou em formação continuada. Nesse tocante, o uso de ferramentas específicas auxilia, sobremaneira, na aprendizagem de novos conceitos e na organização de dados para pesquisa.

No aspecto teórico referente à Meta 4, componente 2 do Projeto Rede Guarani/Serra Geral, o que ficou evidenciado é que por ser a água um recurso que merece intensa proteção, de um modo geral, todos os entes da federação visam, por meio de leis ou normas administrativas, regulamentar seu uso pelos particulares. Todavia, o fato de tal bem ensejar uma proteção ampla, não pode permitir que existam impropriedades conceituais que levem, direta ou indiretamente, a uma complexa e insegura aplicação prática das repartições de competências, na medida em que, por vezes, impossibilita a correta aplicação dos preceitos constitucionais.

Por fim, destaca-se que propostas inovadoras de ensino e pesquisa devem ser fomentadas no âmbito da Universidade, ainda que de forma adaptada, posto que, é compromisso das Instituições Universitárias produzir conhecimento científico capaz de atender às demandas sociais em tempos de complexidade.

\section{REFERÊNCIAS}

ARAÚJO L.M; FRANÇA A.B; POTTER P.E. Aqüífero Gigante do Mercosul no Brasil, Argentina, Uruguai e Paraguai: mapas hidrogeológicos das Formações Botucatu, Pirambóia, Rosário do Sul, Buena Vista, Missiones e Taquarembó. Curitiba: UFPR/Petrobrás, 1995.

DEMO, Pedro. Educar pela pesquisa. 4.ed. São Paulo: Autores Associados, 2000.

GOWIN, D. Bob; NOVAK, Joseph D. Aprender a aprender. Lisboa: Plátano Universitária, 1984.

KREPSKY, Giselle Marie. Como o aluno aprende? A importância da ação reflexiva na construção do conhecimento. Revista Jurídica, Blumenau, ano 10, n.19, jan-jun 2006, p.217-230.

MASINI, Elcie F. Salzano; MOREIRA, Marco Antonio. Aprendizagem significativa: a teoria de David Ausubel. São Paulo: Centauro, 2002.

MOREIRA, Marco Antonio; BUCHWEITZ, Bernardo. Mapas Conceituais: instrumentos didáticos, de avaliação e de análise de currículo. São Paulo: Moraes Ltda., 1987.

MORIN, Edgar. 0 Método 3: 0 conhecimento do conhecimento. 3.ed. Porto Alegre: Sulina, 2008.

PIAGET, Jean et al. Seis estudos de psicologia. Tradução de Maria Alice M. D’ Amorim e Paulo Sérgio L. Silva. Rio de Janeiro: Forense, 1969.

POMPEU, Cid Tomanik. Direito de Águas no Brasil. 2.ed. São Paulo: Revistas dos Tribunais, 2011.

WOLKMER, M. F. S; SCHEIBE, L. F; HENNING, L. A. A Rede Guarani/Serra Geral: Um Projeto em Movimento. In: TREVISOL; J. V. SCHIEBE, L. F. Bacia hidrográfica do rio do Peixe: Natureza e Sociedade. Joaçaba-SC: Unoesc, 2011, p.361-380. 
1. Doutoranda em Direito pela Universidade do Vale do Rio dos Sinos (UNISINOS), Mestre em Educação pela Fundação Universidade Regional de Blumenau (FURB), professora titular do Curso de Direito da FURB, pesquisadora integrante do Grupo de Pesquisa CNPq: Direitos Fundamentais, Cidadania e Novos Direitos, atuando nas linhas: Sistema Jurídico e Produção do Conhecimento e Direito Ambiental, sustentabilidade e políticas públicas de água, prevenção de desastres e sanitária, Departamento de Direito, Centro de Ciências Jurídicas. E-mail: gkrepsky@furb.br.

2. Mestre em Desenvolvimento Regional pela Fundação Universidade Regional de Blumenau (FURB), professora substituta do Curso de Direito da FURB, pesquisadora integrante do Grupo de Pesquisa CNPq: Direitos Fundamentais, Cidadania e Novos Direitos com atuação na linha de pesquisa Direito Ambiental, sustentabilidade e políticas públicas de água, prevenção de desastres e sanitária do Departamento de Direito, do Centro de Ciências Jurídicas, FURB. E-mail: liamorastoni@yahoo.com.br.

3. Mestrando em Engenharia Ambiental na FURB (Fundação Universidade Regional de Blumenau), bolsista de pesquisa $\mathrm{CNPq}$ vinculado ao PPGEA - FURB (Programa de Pós-Graduação em Engenharia Ambiental), pesquisador integrante do Grupo de Pesquisa CNPq: Direitos Fundamentais, Cidadania e Novos Direitos, atuando na linha: Direito Ambiental, sustentabilidade e políticas públicas de água, prevenção de desastres e sanitária, Departamento de Direito, Centro de Aceito em: 17 de Abril de 2014 